01,07

\title{
Анализ разрушения перлитной рельсовой стали с внутренней макротрещиной
}

\author{
(C) С.А. Атрошенко ${ }^{1}$, С.С. Майер ${ }^{2}$, В.И. Смирнов ${ }^{2}$ \\ ${ }^{1}$ Институт проблем машиноведения РАН, \\ Санкт-Петербург, Россия \\ ${ }^{2}$ Петербургский государственный университет Императора Александра I, \\ Санкт-Петербург, Россия \\ E-mail: satroshe@mail.ru
}

Поступила в Редакцию 28 ноября 2020 г.

В окончательной редакции 28 ноября 2020 г.

Принята к публикации 2 декабря 2020 г.

Рассмотрен один из наиболее опасных дефектов, приводящих к поперечным изломам рельсов, а именно внутренние поперечные трещины в головке рельса. Выполнен фрактографический анализ поверхности сечения рельса с поперечной усталостной трещиной. Рельсовая проба изъята из эксплуатации после многолетнего срока службы. Микроструктурный анализ поверхности трещины и окружающего ее материала показывает существенную деградацию физико-механических свойств рельсовой стали.

Ключевые слова: рельсовая сталь, металлография, усталостная трещина, микроструктура металла, поверхность разрушения.

DOI: 10.21883/FTT.2021.05.50803.244

\section{1. Введение}

Наличие ряда неблагоприятных факторов металлургического и технологического характера приводит к возникновению в рельсах различных дефектов, в частности, внутренних поперечных трещин в головке. Подвергаясь значительным силовым воздействиям от подвижного состава, первоначальные трещины с глубиной залегания 2-6 mm от поверхности головки рельса в процессе эксплуатации распространяются от поверхности к середине головки рельса и далее в глубину. Такие трещины являются весьма опасным дефектом, так как не имеют каких-либо наружных признаков, при малых размерах не обнаруживаются дефектоскопами и в запущенной стадии роста могут приводить к поперечным изломам рельса. Кроме того, накопление остаточных напряжений сопровождается деградацией первоначальной структуры рельсовой стали. Наибольшим изменениям подвержены зерна металла, прилегающие к поверхности катания колеса.

Технические требования к рельсам в связи с развитием высокоскоростного и тяжеловесного движения и необходимости повышения их безопасности требуют понимания природы, механизмов и особенностей различных видов разрушений рельсов в эксплуатации. На основании обработки результатов полигонных испытаний рельсов с различной эксплуатационной стойкостью обнаружено [1-9], что большое влияние на стойкость к образованию контактно-усталостных дефектов оказывает однородная и мелкодисперсная микроструктура. Такие параметры микроструктуры рельсов, как величина межпластиночного расстояния в перлите, величина пер- литных колоний, наличие избыточного феррита также оказывают большое влияние на свойства рельсов [8]. Эксплуатационная стойкость металла с более однородной структурой выше и повышается с ростом твердости только у рельсов с гомогенной структурой, при этом наибольшей конструктивной прочностью рельсов, по мнению различных авторов, обладают рельсы либо при однородной структуре сорбита закалки максимальной дисперсности, либо при однородной структуре отпущенного мартенсита.

\section{2. Материал и методика исследования}

Исследования проводились на дифференцированно термоупрочненных железнодорожных рельсах типа Р65 с внутренней поперечной трещиной. В качестве материала исследования использовали три образца рельсовой стали, свойства и элементный состав которой регламентируются ГОСТ Р 51685-2013. Для анализа разрушения были вырезаны рельсовые пробы длиной 1.1-1.2 m, которые испытывались на статический поперечный изгиб с нагружением на подошву образцов рельса с определением показателей прочности и пластичности на прессе ПМС 320.

Доля вязкой составляющей в изломе стали определялась по ASTME 436-03. Исследование поверхности разрушения проводилось на микроскопе Axio Observer Z1-M в темном поле при увеличении 100, а микроструктура поперечного сечения анализировалась в светлом поле и контрасте C_DIC (Circular polarized light - differential interference contrast) на том же микроскопе. 


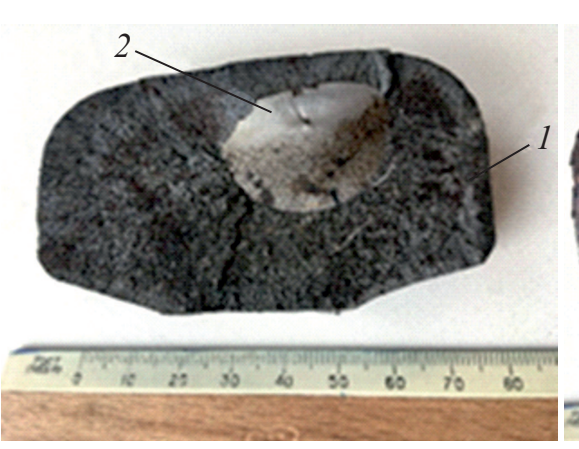

Rail_1

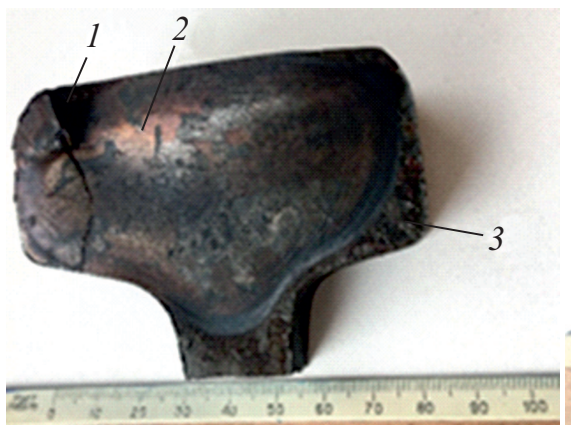

Rail 2

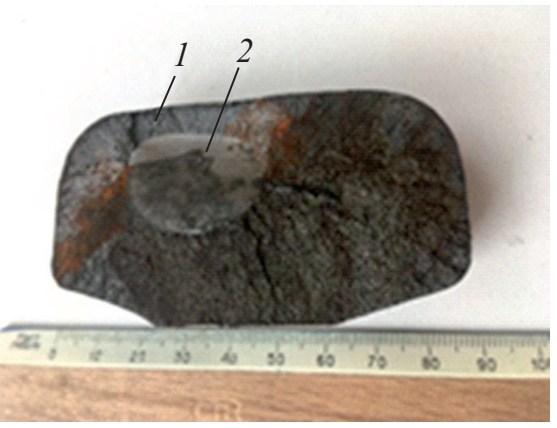

Rail_3

Рис. 1. Поверхность разрушения испытанных образцов рельсов.

$a$
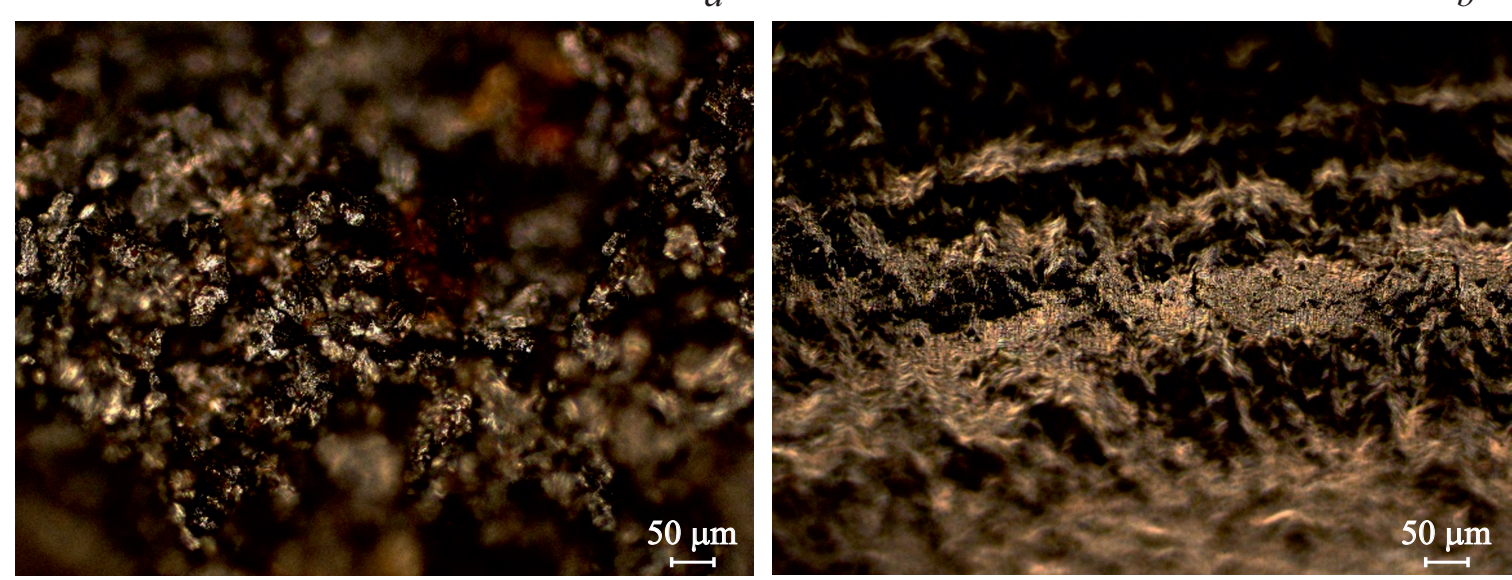

Рис. 2. Вид поверхности разрушения образца Rail_1 в первой $(a)$ и во второй $(b)$ области.

\section{3. Результаты и их обсуждение}

Данные испытаний на трехточечный изгиб и наименьшие приемочные показатели испытанных рельсовых проб приведены в табл. 1. Срок службы изъятых из эксплуатации рельсов 18-19 лет. За этот срок рельсы подверглись ориентировочно $22 \cdot 10^{6}, 53.6 \cdot 10^{6}$ и $3.27 \cdot 10^{6}$ циклам нагружения, т.е. проходам колеса

Таблица 1. Данные испытаний и приемочные показатели испытанных рельсовых проб

\begin{tabular}{c|c|c|c|c}
\hline Образец & $F, \mathrm{kN}$ & $L, \mathrm{~mm}$ & $F_{\min }, \mathrm{kN}$ & $L_{\min }, \mathrm{mm}$ \\
\hline Rail_1 & 86 & 2.2 & 1750 & 23 \\
\hline Rail_2 & 195 & 5.2 & 1750 & 23 \\
\hline Rail_3 & 540 & 5.4 & 1750 & 23
\end{tabular}

Примечание. $F-$ разрушающая нагрузка и $L-$ стрела прогиба, данные после испытаний на статический поперечный изгиб, $F_{\min }, L_{\min }$ - наименьшие (допускаемые) приемочные показатели прочности и жесткости при статическом поперечном изгибе с нагружением на подошву рельса. (соответственно образцы Rail_1, 2 и 3). Как видно из табл. 1, все испытанные рельсовые пробы совершенно не удовлетворяют нормативным требованиям прочности и жесткости, что свидетельствует о запоздалом обнаружении дефектов.

\section{1. Исследование поверхности разрушения}

Внешний вид поверхности разрушения испытанных образцов представлен на рис. 1, а доля вязкой составляющей на поверхности излома (\% В) представлена в табл. 2. В этой таблице области измерения вязкой составляющей соответствуют указанным на рис. 1: область 2 - поверхность усталостной трещины, области 1,3 - зоны долома образца. В табл. 2 также представлено количество волокна в переходной зоне (transition) для Rail_1 и Rail_3 образцов.

Как видно из табл. 2 и из рис. 2-4, в образцах Rail_1 и Rail_3 более хрупкое разрушение наблюдается на поверхности трещины. Что касается образца Rail_2, то здесь более хрупкой является прифронтовая поверхность трещины, затем по мере развития трещины в глубину хрупкость снижается. 
$a$

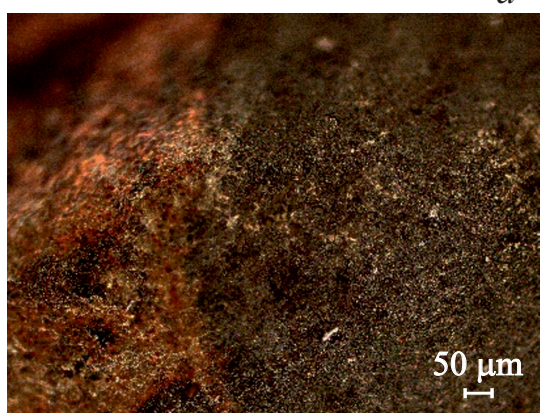

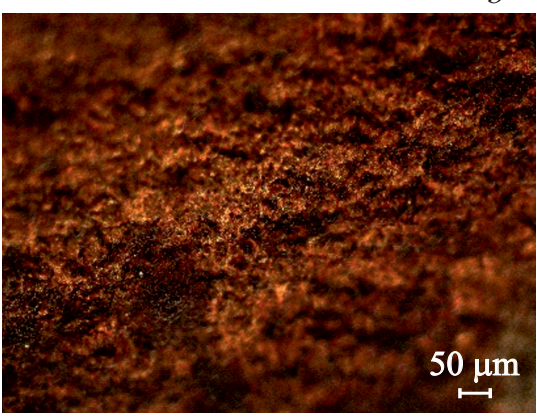

C

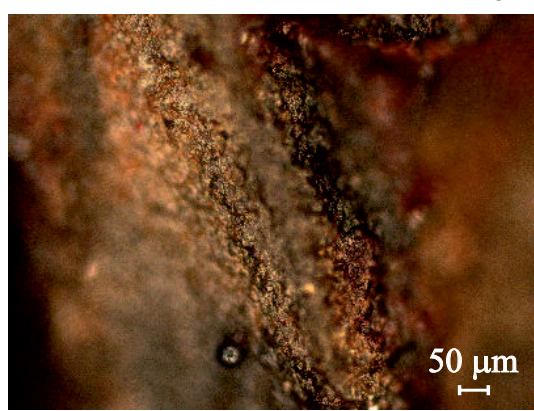

Pис. 3. Вид поверхности разрушения образца Rail_2 в первой $(a)$, второй $(b)$ и третьей $(c)$ областях.

$a$

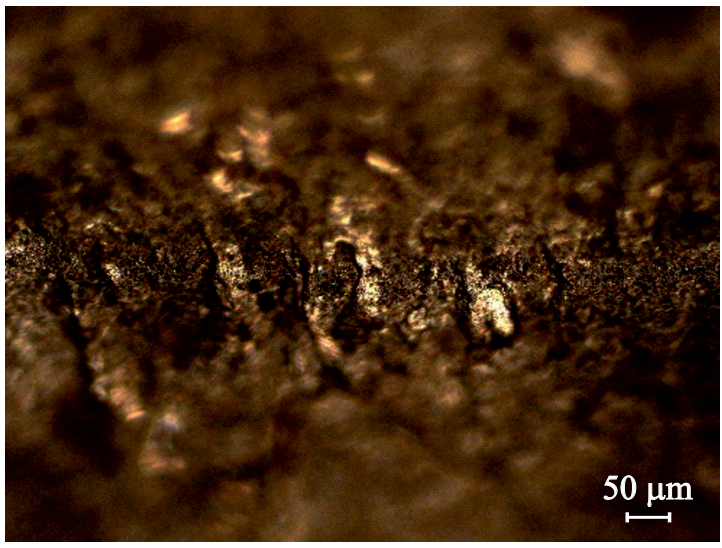

$b$

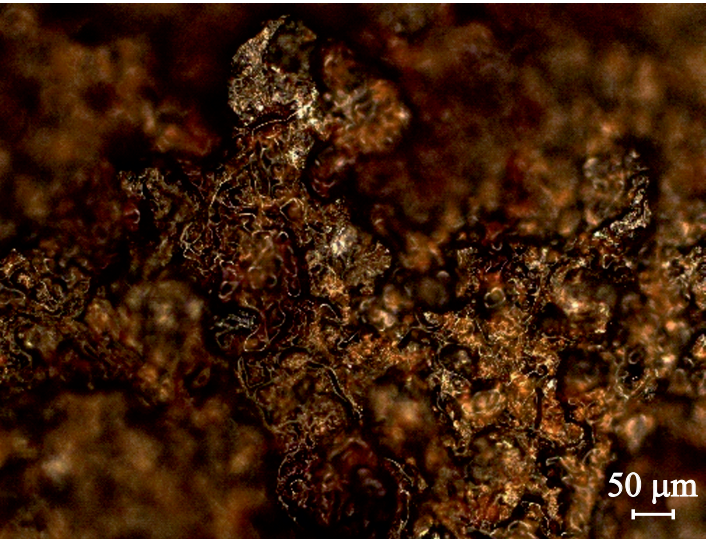

Pис. 4. Вид поверхности разрушения образца Rail_3 в первой $(a)$ и второй $(b)$ областях.

Такое поведение металла становится более понятным после исследования микроструктуры поперечных шлифов в соответствующих областях разрушения.

\section{2. Исследование микроструктуры поперечных шлифов рельсовых образцов}

\subsubsection{Rail_1}

\section{1) Область 1}

Структура поверхности образца Rail_1 в области 1 (рис. 1, долом рельса) представлена на рис. 5.

Видна анизотропия (направленность структуры) вблизи поверхности разрушения, а также пористость (рис. 5,a), присутствуют микротрещины, идущие от поверхности разрушения вглубь материала (рис. $5, b$ ) и вдоль прокатки (рис. 5,c). На рис. $5, d$ видна структура пластинчатого перлита, а на рис. 5, $c$ - зоны динамической рекристаллизации, аналогичные выявленным в [10]. Количественная оценка микроструктурных элементов приведена в табл. 3.

\section{2) Область 2}

Структура области 2 (рис. 1, поверхность трещины), представлена на рис. 6. Видны микротрещины в приповерхностной области разрушения (рис. $6, a)$. На некото-
Таблица 2. Доля вязкой составляющей (\%B) в изломе рельсовых сталей

\begin{tabular}{c|c|c}
\hline Образец & Область & $\% \mathrm{~B}$ \\
\hline \multirow{2}{*}{ Rail 1 } & 1 & 97.04 \\
\cline { 2 - 3 } & 2 & 92.18 \\
\cline { 2 - 3 } & Переходная зона & 97.60 \\
\hline \multirow{2}{*}{ Rail 2 } & 1 & 96.18 \\
\cline { 2 - 3 } & 2 & 97.61 \\
\cline { 2 - 3 } & 3 & 92.45 \\
\hline \multirow{2}{*}{ Rail 3 } & 1 & 96.96 \\
\cline { 2 - 3 } & 2 & 92.08 \\
\cline { 2 - 3 } & Переходная зона & 96.10
\end{tabular}

ром расстоянии от поверхности разрушения наблюдается полоса с избыточным ферритом в виде ферритной сетки (рис. $6, b)$ и зерен феррита (рис. 6,e), что вызывает охрупчивание материала (табл. 2,3). В отдельных областях наблюдается динамическая рекристаллизация 


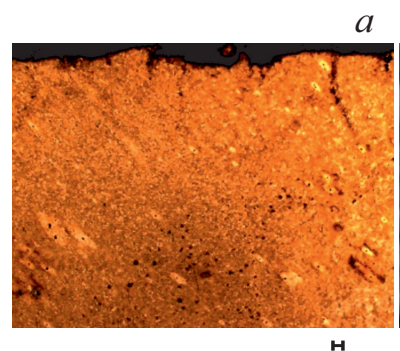

$100^{\mathbf{H}} \mu \mathrm{m}$

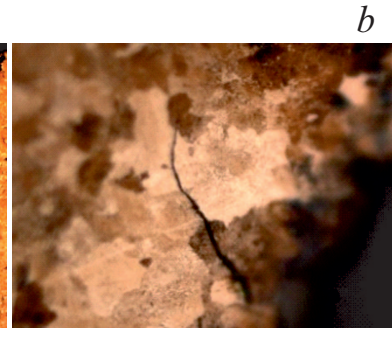

$20 \stackrel{\mathrm{H}}{\mu \mathrm{m}}$

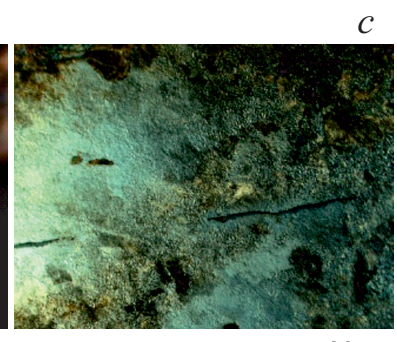

$5 \stackrel{H}{\mu m}$

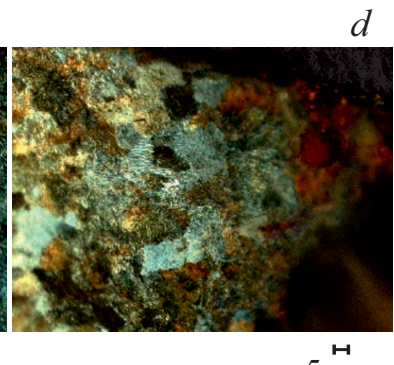

$5 \stackrel{H}{\mu \mathrm{m}}$

Pис. 5. Структура области 1 образца Rail_1: $a-\mathrm{x} 25 ; b-\mathrm{x} 1000 ; c, d-\mathrm{x} 1000$ (C_DIC).

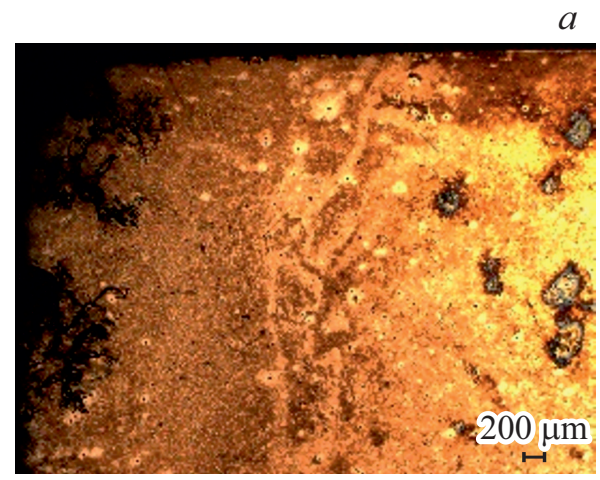

$a$
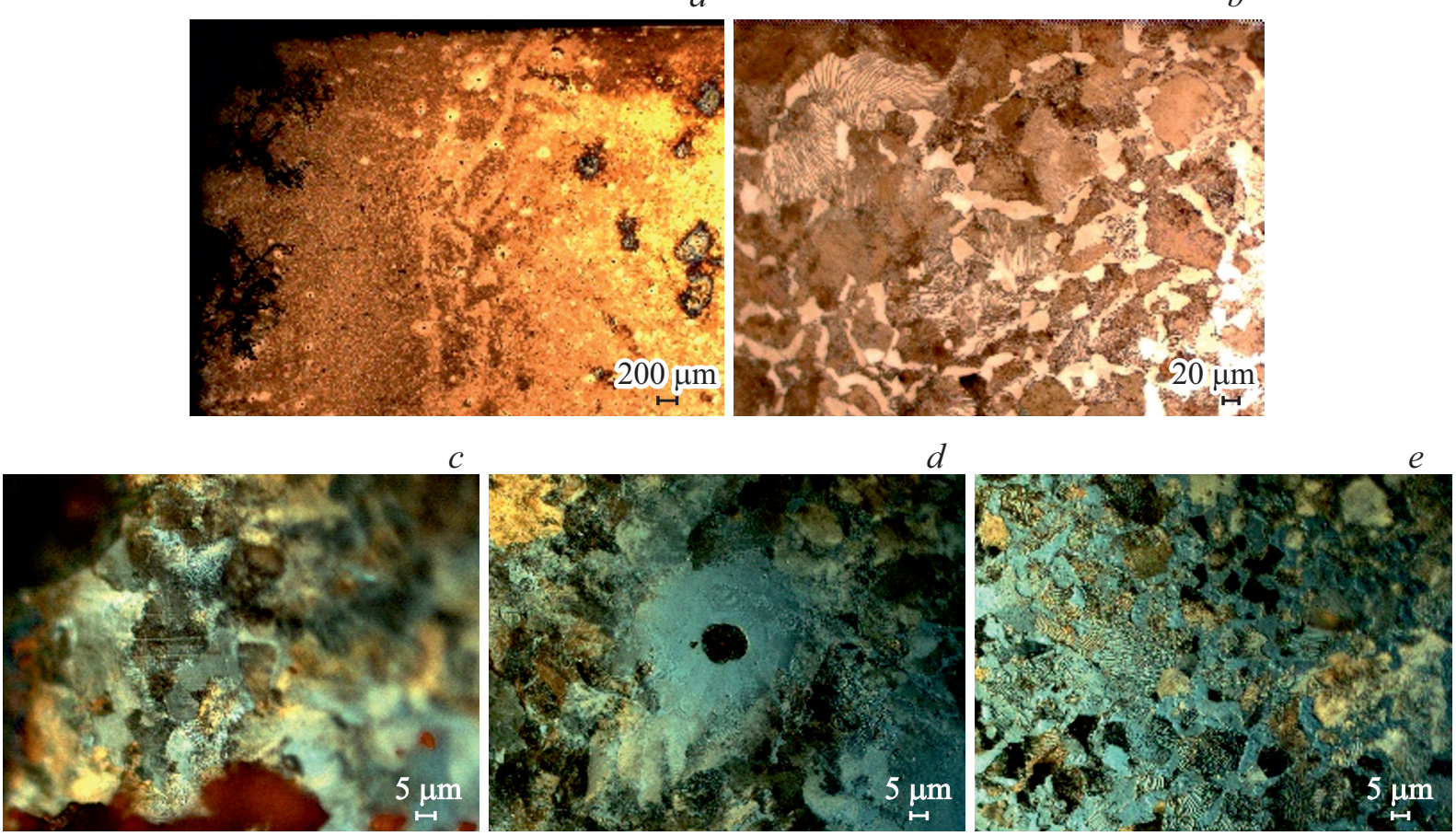

Pис. 6. Структура области 2 образца Rail_1: $a-\mathrm{x} 25 ; b-\mathrm{x} 2500 ; c, d, e-\mathrm{x} 1000$ (C_DIC).

(рис. 6,d) и отдельные двойники (рис. 6,c). Наличие двойников больше характерно для металлов с ГЦКи ГПУ-кристаллическими решетками, которые обладают более низкой энергией дефектов упаковки (ЭДУ), чем металлы с ОЦК-решеткой, к которой относится исследуемая сталь. Появление двойников связано с мартенситным превращением и появлением двойникованного мартенсита (табл. 3).

\subsubsection{Rail_2}

\section{1) Область 1}

Структура поверхности образца Rail_2 в области 1 (рис. 1, долом рельса) представлена на рис. 7.

В процессе циклической пластической деформации образуется наклепанный слой с микроструктурой волокнисто-деформированного перлита [6], что и наблюдается в этой области разрушения - в приповерхностной зоне видны следы течения (рис. 7,a) металла, где все структурные элементы перемешались, микротрещины идут вдоль областей феррита (рис. 7, $b, c$ ), в некоторых местах образца видны зоны динамической рекристаллизации (рис. $7, d)$, аналогичные обнаруженным в [10].

2) Область 2

Структура материала в наиболее протяженной области разрушения 2 (рис. 1, поверхность усталостной трещины) образца Rail_2 приведена на рис. 8.

От поверхности усталостной трещины образца Rail_2 отходит сетка микротрещин (рис. 8,a). Зарождение последних происходит на неметаллических включениях (рис. $8, b)$, богатых серой и кислородом, что наблюдалось и на других рельсовых пробах [10]. На рис. 8, видна структура пластинчатого перлита и отдельные зерна феррита, а на рис. $8, d-$ ферритная сетка. 
Таблица 3. Количественные характеристики микроструктуры рельсовой стали в различных областях разрушения

\begin{tabular}{|c|c|c|c|c|c|c|c|}
\hline Образец & Область & $D_{g}, \mu \mathrm{m}$ & $h_{\text {perlite }}, d_{p}, \mu \mathrm{m}$ & $L_{\mathrm{tw}}, \mu \mathrm{m} \times H_{\mathrm{tw}}, \mu \mathrm{m}$ & $h_{\text {ferrite }}, d_{f}, \mu \mathrm{m}$ & $\begin{array}{c}\text { Мартенсит, } \\
\text { двойники }\end{array}$ & $\begin{array}{l}\text { Избыток } \\
\text { феррита }\end{array}$ \\
\hline \multirow[t]{2}{*}{ Rail_1 } & 1 & $20.0(8.0-45.3)$ & $h=0.6(0.3-1.0)$ & - & - & & \\
\hline & 2 & $11.1(3.7-20.1)$ & $h=0.4(0.3-0.6)$ & $\begin{array}{c}18.3(13.7-21.5) \cdot 0.5 \\
(0.4-0.6)\end{array}$ & $\begin{array}{c}h=1.4 \\
(0.8-2.4)\end{array}$ & $\begin{array}{c}\text { Мартенсит, } \\
\text { двойники }(16 \%)\end{array}$ & $\begin{array}{c}\text { Сетка и редко } \\
\text { зерна }(9 \%)\end{array}$ \\
\hline \multirow[t]{3}{*}{ Rail_2 } & 1 & $8.0(4.0-12.0)$ & $h=0.4(0.3-0.7)$ & - & $\begin{array}{c}h=2.6 \\
(0.5-1.6)\end{array}$ & & Сетка $(21 \%)$ \\
\hline & 2 & $12.0(5.5-17.5)$ & $h=0.7(0.4-1.5)$ & - & $\begin{array}{c}h=1.1 \\
(0.4-1.8)\end{array}$ & & $\begin{array}{c}\text { Тонкая сетка } \\
+ \text { зерна }(45 \%)\end{array}$ \\
\hline & 3 & $6.7(3.0-11.4)$ & $\begin{array}{l}h=4.0(3.0-5.0) \\
d=1.0(0.8-1.0)\end{array}$ & - & - & & - \\
\hline \multirow[t]{2}{*}{ Rail_3 } & 1 & $15.8(11.3-22.7)$ & $h=1.0(0.3-1.6)$ & - & $\begin{array}{l}h=5.0(1.5-5.8) \\
d=8.2(5.8-14.9)\end{array}$ & & $\begin{array}{c}\text { Сетка } \\
+ \text { +зрна } \\
(11 \%)\end{array}$ \\
\hline & 2 & $13.1(7.0-21.6)$ & $h=0.7(0.5-0.8)$ & $\left|\begin{array}{c}24.2(24.0-24.3) \cdot 0.8 \\
(0.3-1.4)\end{array}\right|$ & $h=1.2(0.6-1.8)$ & $\left|\begin{array}{c}\text { Мартенсит, } \\
\text { двойники }(10 \%)\end{array}\right|$ & Сетка $(48 \%)$ \\
\hline
\end{tabular}

Пр и м е ч ан и е. $D_{g}-$ размер зерна; $h_{\mathrm{perlite}}-$ межпластиночное расстояние в перлите, $d_{p}-$ диаметр глобулярного перлита; $L_{\mathrm{tw}} \times H_{\mathrm{tw}}-$ размеры двойников; $h_{\text {ferrite }}$ - толщинаферритной сетки, $d_{f}-$ размер ферритного зерна.

$a$

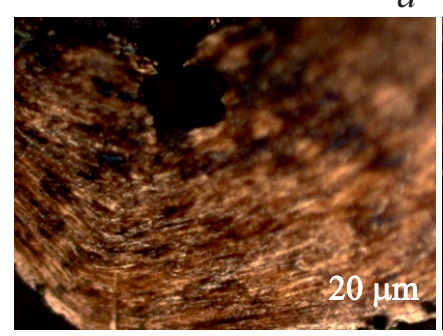

$b$

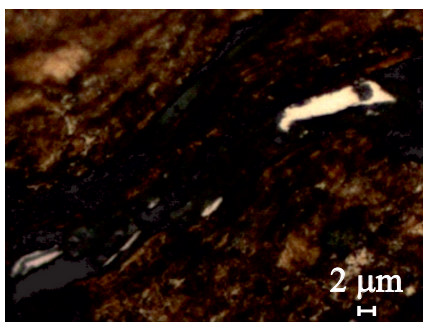

$c$

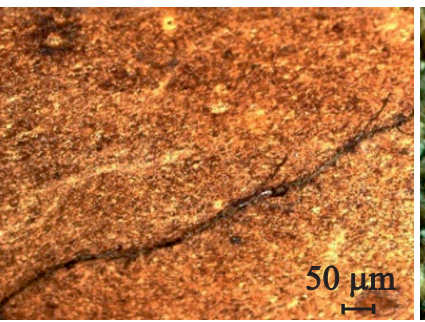

d

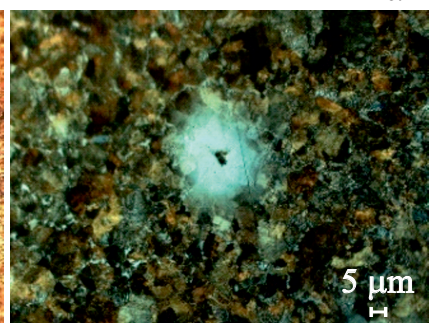

Pис. 7. Структура области 1 образца Rail_2: $a-\mathrm{x} 1000 ; b-\mathrm{x} 2500 ; c-\mathrm{x} 200 ; d-\mathrm{x} 1000$ (C_DIC).

$a$

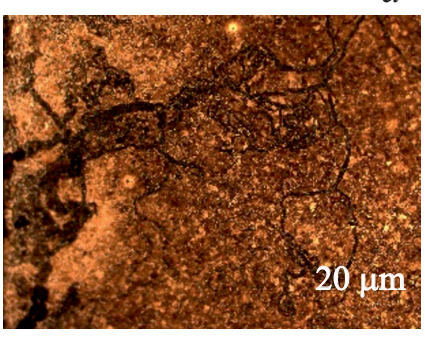

$b$

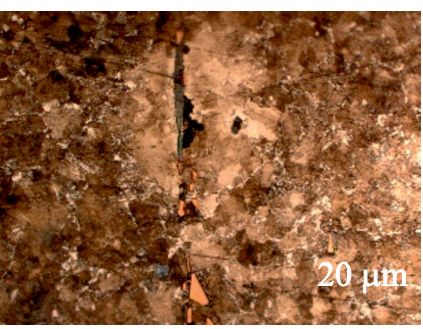

$c$

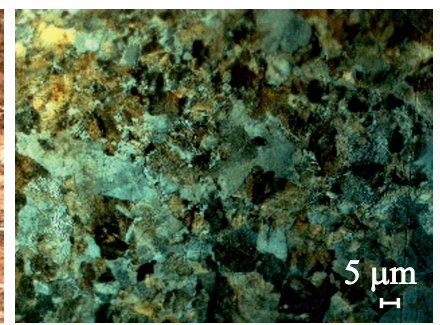

d

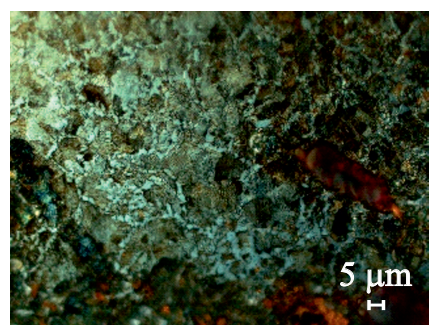

Рис. 8. Структура области 2 образца Rail_2: $a-\mathrm{x} 200 ; b-\mathrm{x} 1000 ; c, d-\mathrm{x} 1000$ (C_DIC).

\section{3) Область 3}

Структура стали в области 3 (рис. 1) представлена на рис. 9.

В этой области зерна имеют неравноосную вытянутую вдоль прокатки форму (рис. 9, $a$ ) (волокнистодеформированный перлит), микротрещины идут по границам зерен феррита (рис. 9, $b$ ). Наблюдаются зоны динамической рекристаллизации и большое количество пор (рис. 9,c). На снимках также виден глобулярный перлит, который появился в результате превращения пластинчатого перлита при нагреве стали в процессе работы рельса.

\subsubsection{Rail_3}

\section{1) Область 1}

Структура поверхности образца Rail_3 в области 1 (рис. 1, долом рельса) представлена на рис. 10. 
$a$
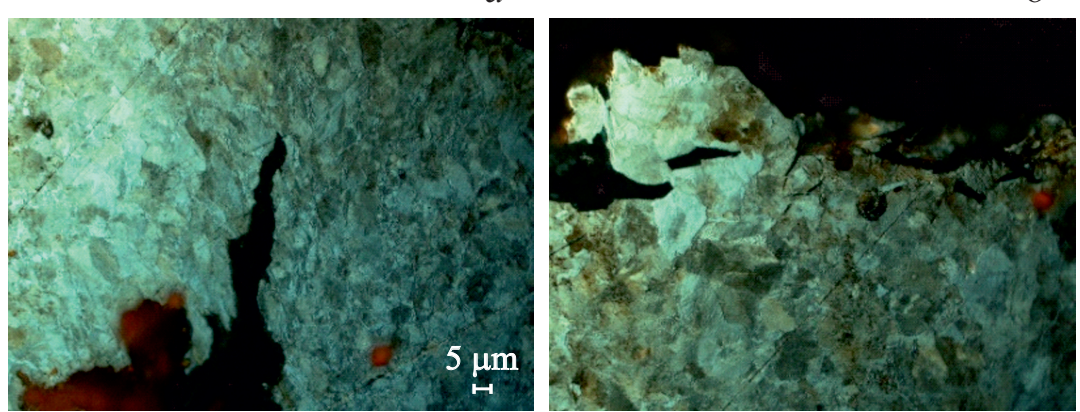

$b$

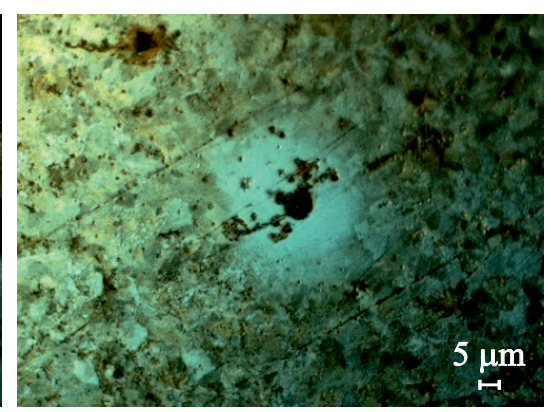

Рис. 9. Структура области 3 образца Rail_2: x1000 (C_DIC).
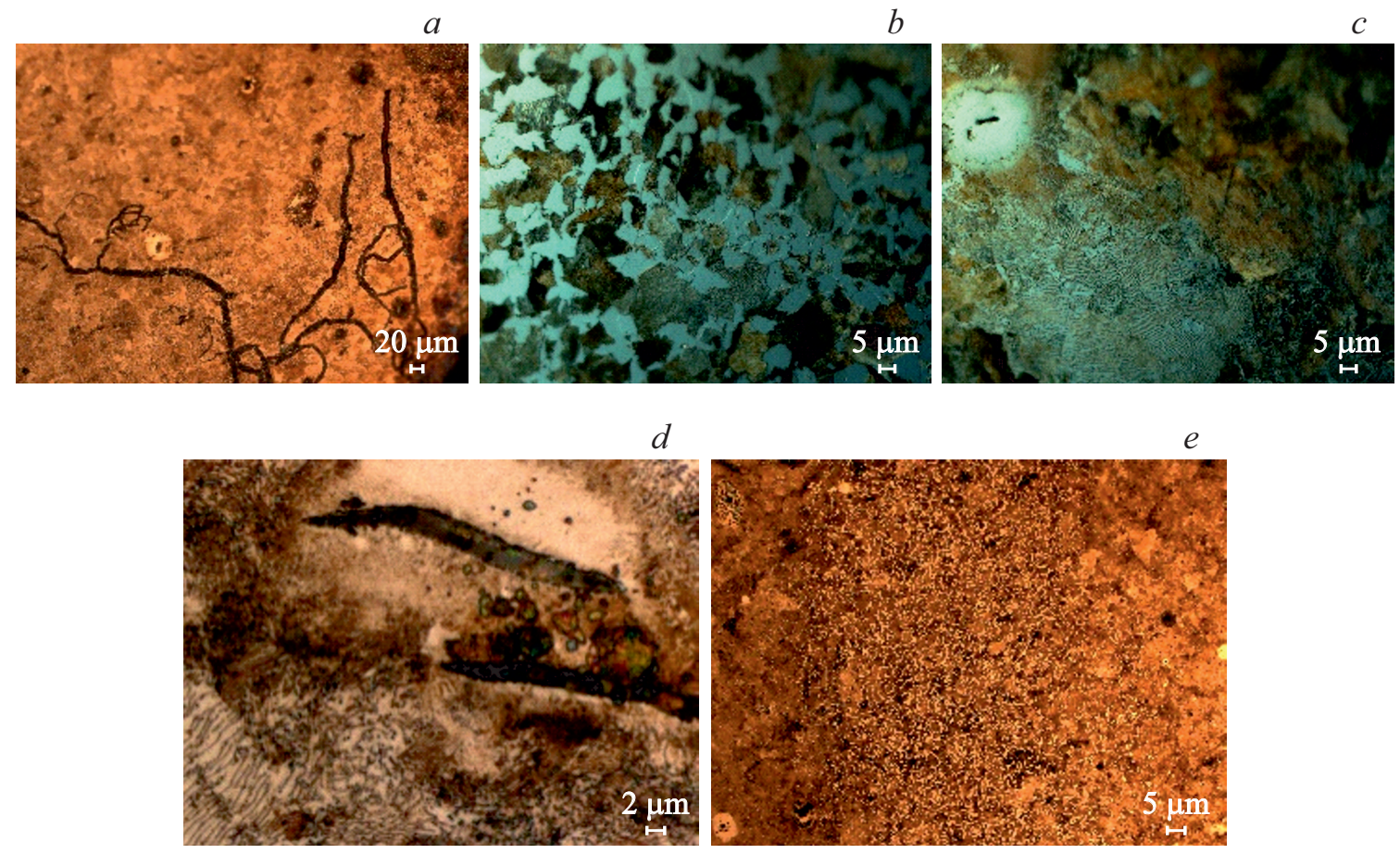

Pис. 10. Структура области 1 образца Rail_3: $a-\mathrm{x} 200 ; b, c-\mathrm{x} 1000$ (C_DIC), $d-\mathrm{x} 2500, e-\mathrm{x} 100$.
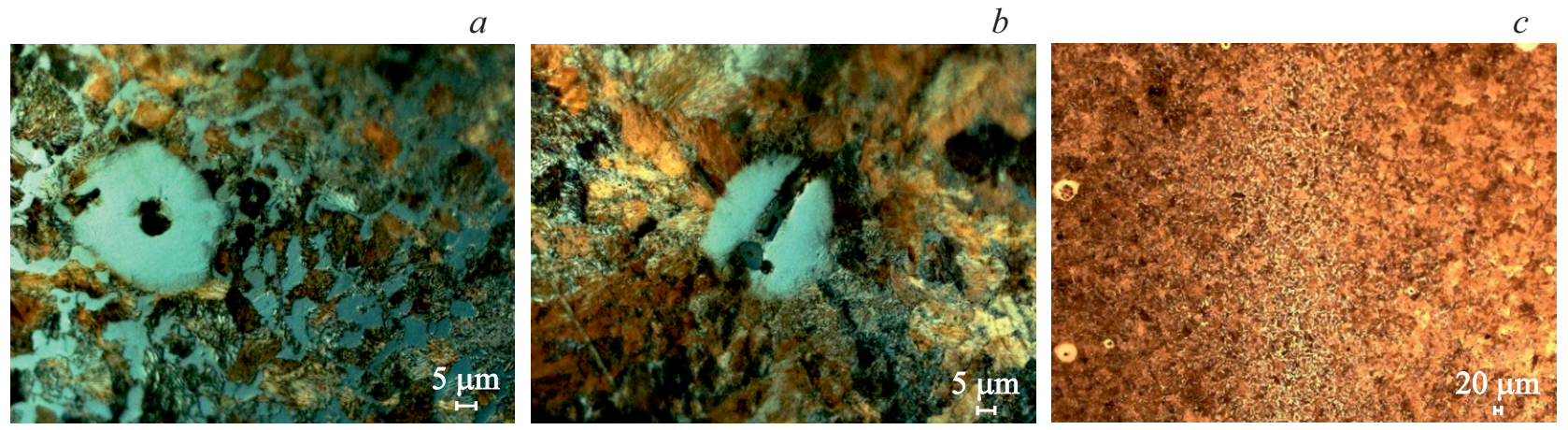

Pис. 11. Структура области 2 образца Rail_3: $a, b-\mathrm{x} 1000$ (C_DIC), $c-\mathrm{x} 100$. 
Вблизи поверхности разрушения наблюдается сетка микротрещин (рис. 10,a), глубже от поверхности разрушения видно много ферритных зерен (рис. 10, $b$ ). Присутствуют также области динамической рекристаллизации наряду с довольно крупными зернами пластинчатого перлита (рис. 10,c). Микротрещины идут по ферритной сетке и в ферритных зернах (рис. 10,d). На рис. 10, е представлена полоса избыточного феррита в виде ферритной сетки.

\section{2) Область 2}

На рис. 11 представлена структура поверхности образца Rail_3 в области 2 (поверхность усталостной трещины).

Присутствуют зоны динамической рекристаллизации (рис. $11, a)$, а на рис. $11, b$ видно зарождение трещины на неметаллических включениях, также видны двойники. Избыточный феррит представлен в виде сетки (рис. $11, c$ ), что способствует охрупчиванию стали.

\section{4. Заключение}

1. Значительное влияние на сопротивление усталостному разрушению оказывает объем феррита в зоне образования трещины: чем оно меньше, тем выше устойчивость к разрушению.

2. На поверхности разрушения исследованных образцов рельсовой стали выделяются области, отличающиеся по хрупкости: наиболее хрупкое разрушение в образцах Rail_1 и Rail_3 наблюдается на стадии усталостного роста трещины, где наблюдается избыточный феррит в виде разветвленной сетки, которая занимает большую площадь поверхности, а также присутствует мартенсит и двойники, что способствует снижению пластичности.

3. Образец Rail_2 отличается наибольшей хрупкостью в приповерхностной области головки рельса, что можно объяснить наличием грубой ферритной сетки с самой большой толщиной, а также самым дисперсным перлитом.

4. Наиболее высокая разрушающая нагрузка и стрела прогиба наблюдаются для образца Rail_3, что объясняется не только меньшим размером трещины, по сравнению с другими пробами, но и наличием мартенсита, мелкодисперсного перлита с относительно мелким зерном, а также динамической рекристаллизацией с образованием микрокристаллических зон высокой твердости.

\section{Конфликт интересов}

Авторы заявляют, что у них нет конфликта интересов.

\section{Список литературы}

[1] Е.А. Шур. Повреждение рельсов. Интекст, М. (2012). $192 \mathrm{c}$.

[2] А.Ю. Абдурашитов. РСП Эксперт 66, 10, 21 (2014).
[3] W. Harris, S.M. Zakharov, J. Lundgren, H. Tournay, W. Ebersohn. Guidelines to best practices for heavy haul railway operations: wheel and rail interface issues. International Heavy Haul Association 2808 Forest Hill Court Virginia Beach, Virginia 23454, USA (2001). 408 p.

[4] M. Dembosky. Permanent Way Institution 124, 2, 72 (2006).

[5] G. Girsch, R. Heyder. Railway Gazette Int. 1, 42 (2004).

[6] Е.А. Шур, А.И. Борц, А.В. Сухов, А.Ю. Абдурашитов, Л.В. Базанова, К.Л. Заграничек. Вестн. ВНИИЖТ 3, 3 (2015).

[7] Е.А. Шур, В.М. Федин, А.И. Борц, Ю.В. Ронжина, А.И. Фимкин. Вестн. ВНИИЖТ 4, 210 (2019).

[8] Е.В. Полевой, А.Б. Добужская, М.В. Темлянцев. Вестн. ПНИПУ 18, 4, 7 (2016).

[9] Ю.Ф. Иванов, К.В. Морозов, О.А. Перегудов, В.Е. Громов. Изв. вузов Черная металлургия 59, 576 (2016).

[10] С.А. Атрошенко, С.С. Майер, В.И. Смирнов. ФТТ 62, 10, 1573 (2020).

Редактор Ю.Э. Китаев 